\title{
Life-style of Rural Secondary School Children in Bangladesh with Particular Emphasis to Physical Exercise and Diet
}

\author{
Md. Nurul Amin, ${ }^{1}$ Md. Jawadul Haque, ${ }^{2}$ Md. Entekhab-Ul-Alam, ${ }^{3}$ Shathi Kumar Rawson Kamal Md. Abu Syem Shah Amanath Ullah, ${ }^{4}$ \\ Nelofar Yasmin, ${ }^{5}$ Farhana Yasmin, ${ }^{6}$ Asadur Rahman, ${ }^{7}$ Shubhra Prakash Paul, ${ }^{8}$ Kowsarunahhar, ${ }^{9}$ Anamica Adhikary, ${ }_{1}^{10}$ Jannatul Ferdous, ${ }^{11}$ Afsana Ali 12
}

Background \& objective: With rapid improvement of socioeconomic condition of developing countries in the last two decades, a rapid change in the nutritional behaviour and activity of adolescents is evident leading to increased prevalence of overweight and obesity among them. The present cross-sectional survey was undertaken to evaluate the dietary and exercise behavior of the adolescents studying in rural secondary schools.

Methods: This study was conducted in the Department of Community Medicine, Rajshahi Medical College, Rajshahi from April-May 2019. Data were collected from secondary schools of Puthia. A total of 535 students from two secondary schools participated in the study. In order to ensure an equal representation from both sexes we chose one boys' and one girls' schools. Every alternate students of those schools from class VI-X were then included in study as respondents. Weight and height of the selected students were first taken followed by interview.

Result: In the present study $15 \%$ of the secondary school children were found underweight and $18 \%$ were overweight or obese. About $65 \%$ of the of the respondents' family were more or less financially solvent. Fifty percent of the adolescents reported that they were accustomed to a healthy balanced diet with $45 \%$ reportedly taking fruits and $60 \%$ taking plenty of vegetables every day. But only $17.3 \%$ took 3 or more servings of fruits a day (the minimum recommended fruit intake). Thirty percent of the adolescents were used to having high carbohydrate and fat. In terms of exercise practice, two-thirds (67.3\%) of the students had healthy practice. The predominantly practiced exercise was running $(65 \%)$ followed by cycling $(64.4 \%)$, playing cricket $(63.6 \%)$, football $(57.2 \%)$ and fast walking $(52.2 \%)$. However, with respect to number of days of exercise in a week and duration of exercise each day a sizable portion of the students' practice was not considered an ideal one. The respondents who did not practice any kinds of exercise or sports activities, most frequently mentioned their 'preoccupation with coaching or private tutors' $(79.4 \%)$ as reasons of inactivity, followed by non-encouragement about playing by their parents $(71.4 \%)$ and teachers $(65.5 \%)$. Nearly $60 \%$ were interested to play but they did not have any playing field nearby home. Nearly one-third of the students pass $>1$ hour of their leisure time by watching TV or sitting at computer or playing games or other activities on mobile. Opinion-seeking questionnaire revealed that $20-50 \%$ of the respondents had misconception on healthy diet, food, energy-rich food, balanced diet and their ability to make a healthy choice for food in any one of these food \& diet-related issues. Boys are more likely to be obese and underweight than the girls.

Conclusion: Unhealthy dietary behavior is widespread among secondary school adolescents in rural area. About one-third of the rural secondary school children are physically inactive and predominant reasons of their inactivity are preoccupation with coaching center or private tutors or no incentive for playing from the parents or teachers. The knowledge level of the students on healthy diet and food is not up to the desired level to make healthy choices for food themselves. Both unhealthy dietary behavior \& inactivity might have contributed to inappreciably adverse nutritional status of the secondary level school children.
\end{abstract}

Key words: Life-style, School Children, Physical Exercise, nutritional status adolescents, diet etc.

\footnotetext{
Authors' information:

Dr. Md. Nurul Amin, Assistant Professor, Department of Community Medicine, Rajshahi Medical College, Rajshahi \& Executive Editor, Ibrahim Cardiac Medical Journal, Ibrahim Cardiac Hospital \& Research Institute, Shahbag, Dhaka.

2 Dr. Md. Jawadul Haque, Professor \& Head, Department Community Medicine, Rajshahi Medical College, Rajshahi, Bangladesh.

${ }^{3}$ Dr. Md. Entekhab-UI-Alam, MBBS, DPH (DU), Assistant Professor, Department of Community Medicine, Rajshahi Medical College, Rajshgahi.

${ }^{4}$ Dr. Shathi Kumar Rawson Kamal Md. Abu Syem Shah Amanath Ullah, Associate Professor, Institute of Health Technology, Rajshahi Medical College, Rajshahi.

${ }^{5}$ Dr. Nelofar Yasmin, Lecturer, Department of Community Medicine, Rajshahi Medical College, Rajshgahi.

${ }^{6}$ Dr. Farhana Yasmin,Lecturer, Department of Community Medicine, Rajshahi Medical College, Rajshgahi.

Dr. Asadur Rahman, Lecturer, Department of Community Medicine, Rajshahi Medical College, Rajshgahi.

${ }^{8}$ Dr. Shubhra Prakash Paul, Lecturer, Department of Community Medicine, Rajshahi Medical College, Rajshgahi.

${ }^{9}$ Dr. Kowsarunahhar, MBBS, MPH Course (BSMMU), Rajshahi Medical College, Rajshahi

${ }^{10}$ Dr. Anamica Adhikary, MBBS, MPH Course (BSMMU), Rajshahi Medical College, Rajshahi

${ }^{11}$ Dr. Jannatul Ferdous, MBBS, MPH Course (BSMMU), Rajshahi Medical College, Rajshahi

${ }_{12}^{2}$ Dr. Afsana Ali, MBBS, MPH Course (BSMMU), Rajshahi Medical College, Rajshahi

Correspondence: Dr. Md. Nurul Amin, Mobile:01753178452, e-mail:mdamin01@yahoo.com
} 


\section{INTRODUCTION:}

The World Health Organization (WHO) recognized obesity as a global epidemic in $1997 .{ }^{1}$ In the past 30 years, the prevalence of obesity has doubled in children and quadrupled among adolescents. ${ }^{2}$ Worldwide 43 million children were overweight/ obese in 2010, of which 35 million children are from developing countries. In addition, 92 million were found at risk of having overweight and obesity. ${ }^{3}$ Studies done in developed countries revealed that the prevalence of overweight/obesity among school children is increasing. ${ }^{4-6}$ Establishing eating patterns and physical activity in adolescence can result in dietary habits that continue through adulthood. The WHO Global Strategy on diet, physical activity and health7 highlights that bringing about changes in dietary habits and patterns of physical activity will require the combined efforts of many stakeholders, public and private. Nutrition is one of the important elements for healthy living in school-aged children and it should be given high priority on every school agenda. There is evidence to suggest that improved nutrition enhances learning ability, leading to better academic performance. ${ }^{8}$ The school, therefore, has the responsibility to promote healthy eating patterns whilst acknowledging that improving the nutrition starts of school-aged children is an important investment for future generation. Research shows that school environment influences children attitude, preferences, \& behaviors. Therefore, it is becoming an issue of increasing interest to study the adolescents' nutritional status and eating patterns and exercise.

Physical education and physical activity have an educational value in their own right and provide the child with a more holistic education. There is strong evidence that children and adolescents benefit from physical activity through improved cardiorespiratory \& muscular fitness from, bone health, cardiovascular and metabolic health biomarkers. There is growing body of evidence that inactive children are more likely to become inactive adults $^{9}$ Hence, the importance of introducing physical activity at an early age can help improve academic achievement, including grades and standardized test scores. Physical activity can affect cognitive skills and attitudes and academic behaviour. Increasing or maintaining time dedicated to physical education might help and does not appear to adversely affect academic performances. ${ }^{10}$ Childhood \& adolescents are critical periods and the provision of a healthy diet at this stage reduces the risk of diet-related health conditions including obesity and oral health issues.

In Bangladesh childhood obesity is becoming a growing public health problem not only in the urban areas but also in the rural areas. These days inactivity among children \& adolescents have become pandemic. The wave of widespread inactivity coupled with unhealthy dietary behaviour has added an impetus to the non-communicable diseases. Shaping healthy life-style practice should be initiated during the period of childhood and adolescence. But lack of knowledge of physical activity guidelines for children \& negativity towards physical education at school among adolescents, potentially hinders healthy living. Multiple factors may influence the eating and exercise behaviour of the adolescents. That purpose the present study was undertaken to evaluate perception and practice of rural secondary school children about physical exercise and dietary habits of rural secondary schools in Bangladesh as well as factors that govern their dietary and exercise behaviour.

\section{METHODS:}

This cross-sectional analytical study was carried out in the two secondary schools of Puthia, namely Pthia Girls' High School and P.N. Govt. High School, Puthia, over a period 1 month from April-May 2019. Adolescents (age between 11-18 years or studying at grade VI-X) of the defined secondary schools were the study population. Of them who voluntarily consented (verbal consent) through the School Authority (Headmaster) to participate in the study were included as sample. Students having known chronic diseases like valvular heart diseases or any other systemic diseases that may affect their nutritional status and students remaining absent on the day of interview and students who refused to participate in the study were excluded.

A total of 540 students from two schools (one boys' and one girls' school) were primarily included in the 
study. Of the 540 students five students were from primary schools and hence were excluded leaving 535 students for final analysis. On obtaining permission from the school authority \& verbal consent from the students, the data were collected from the respondents by face-to-face interview. Demographic characteristics (age, sex \& socioeconomic status) including height, weight and grade in the school of all respondents were assessed first. Height was measured without shoes to the nearest centimeter using a ruler attached to the wall, while weight was measured to the nearest $0.1 \mathrm{~kg}$ on a manually-adjusted scale with the subject wearing school dress and no shoes. Using weight and height data, body mass index (BMI) was calculated with help of formula BMI = (weight in $\mathrm{kg}$ )/(height in sq-meter). Nutritional status was determined based on body mass index. As BMI of children and adolescents is age- and sex-specific, calculated BMI was plotted on Growth-chart [developed and recommended by Centre for Disease Control, Atlanta] to find the percentile (Fig.1). Then the nutritional status of the individual respondents was determined as shown in table I:

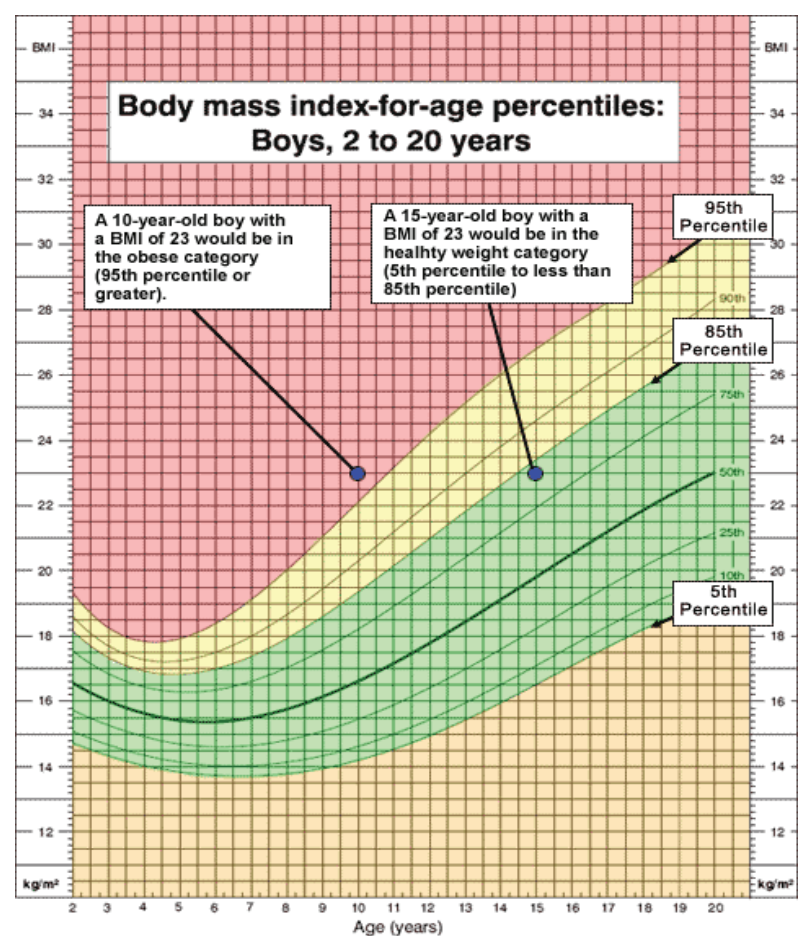

Fig. 1 : Body mass index-for-age percentiles (Adapted from CDC, Atlanta)

\section{BMI for Children and Teens}

- Age- and sex-specific

- Plot BMI on growth chart to find percentile

- Weight status determined by percentile

\begin{tabular}{|c|c|}
\hline $\begin{array}{c}\text { Weight Status Category } \\
\text { Obese }\end{array}$ & $\begin{array}{c}\text { Weight Status Category } \\
\text { Overweight }\end{array}$ \\
\hline Normal & $\mathbf{8 5}^{\text {th }}$ to $<95^{\text {th }}$ percentile \\
\hline Underwentile \\
\hline $5^{\text {th }}$ to $<85^{\text {th }}$ percentile \\
\hline & $<5^{\text {th }}$ percentile \\
\hline
\end{tabular}

Fig. 2 : Nutritional status based on BMI-for-age percentiles (Adapted from CDC, Atlanta)

Then data were collected on eating habits, physical activity \& lifestyle, healthy and unhealthy dietary habit $\&$ food, The pastime (ways of passing leisure time) adopted by the students, reasons of reluctance to take exercise and nutrition knowledge. The following terms were operationalized for uniform and objective evaluation of the students' dietary and exercise behavior.

Unhealthy dietary behavior: When the dietary practice of the participating students were found deviated from that recommended by the Food Guide Pyramid.

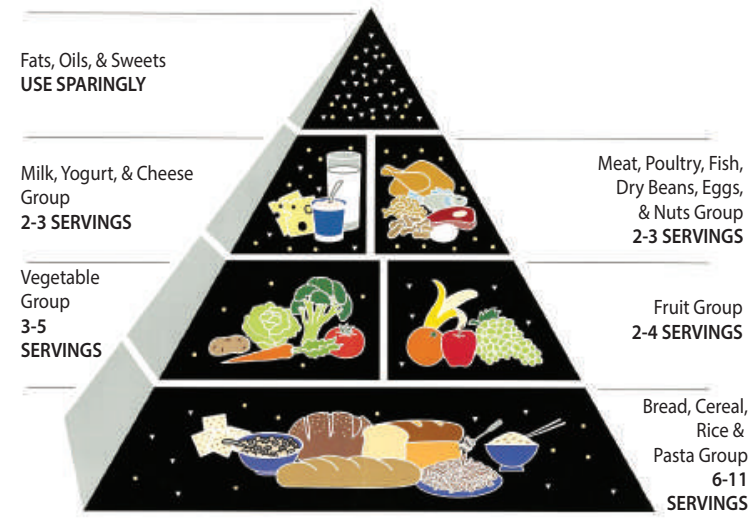

Fig. 3 : Food Guide Pyramid (Source: TH Chan, School of Public Health - Harvard University)

Healthy dietary behavior: When the dietary behaviour of the students conforms with that recommended by the Food Guide Pyramid.

Inactivity: When the students do not practice any outdoor games or take formal exercise at least 5 
days in week with at least 30 minutes duration in each day.

Healthy exercise behaviour: When the students used to practice any outdoor games or take formal exercise at least 5 days in a week with 30 minutes duration in each day, the exercise behaviour was considered normal or healthy

Data processing and analysis were done using SPSS (statistical package for social sciences), version 25.0. The test statistics used to analyze the data were descriptive statistics and Chi-square $\left(\chi^{2}\right)$ Test. The level of significance was set at $5 \%$ and $p$-value $<0.05$ was considered significant.

\section{RESULTS:}

Age distribution shows that nearly half of the students were $13-14$ years old, $32.1 \% \quad 11-12$ years, $19.1 \%$ $15-16$ years and only $1.5 \% 17-18$ years old. The mean age of the respondents was $13.3 \pm 1.4$ years. Gender distribution shows that girls outnumbered boys by 11 : 9 with $54.8 \%$ girls and $45.2 \%$ boys (Table I). Over half of the respondents belonged to middle class family, 29\% lower middle class, $10.7 \%$ upper middle class, $6.5 \%$ poor and $3.6 \%$ rich (Fig.1). Nutritional status was measured in terms of BMI for specific age and sex. Accordingly two-thirds (66.7\%) of the students were of normal BMI (Healthy), $15.1 \%$ underweight, $9.2 \%$ overweight and another $9 \%$ were obese (Fig. 2).

\begin{tabular}{|lcc|}
$\begin{array}{l}\text { Table I. Distribution of students by their demographic } \\
\text { characteristics }(\mathbf{n}=\mathbf{5 3 5})\end{array}$ & \\
\hline $\begin{array}{l}\text { Demographic characteristics } \\
\text { Age* (years) }\end{array}$ & Frequency & Percentage \\
\hline $11-12$ & 172 & 32.1 \\
$13-14$ & 153 & 47.3 \\
$15-16$ & 102 & 19.1 \\
\hline $17-18$ & 8 & 1.5 \\
\hline Sex & & \\
\hline Boys & 293 & 54.8 \\
Girls & 242 & 45.2 \\
\hline
\end{tabular}

*Mean age $=13.3 \pm 1.4$ years; range $=(11-18)$ years; median $=13.0$ years; mode $=13.0$ years

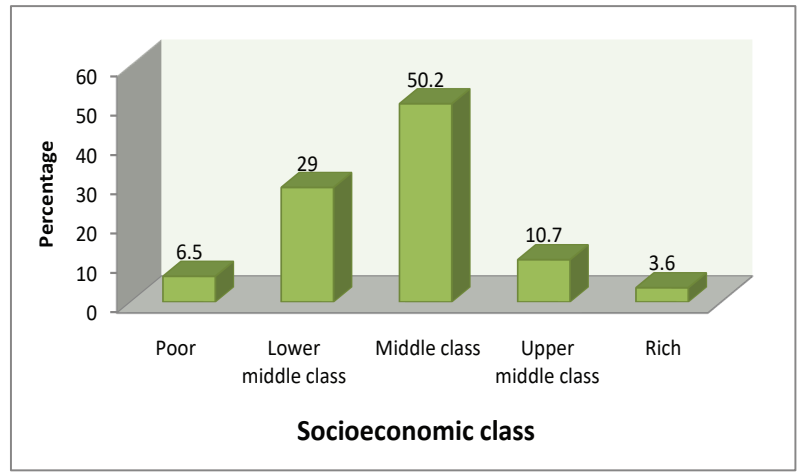

Fig. 1: Distribution of respondents by their social class

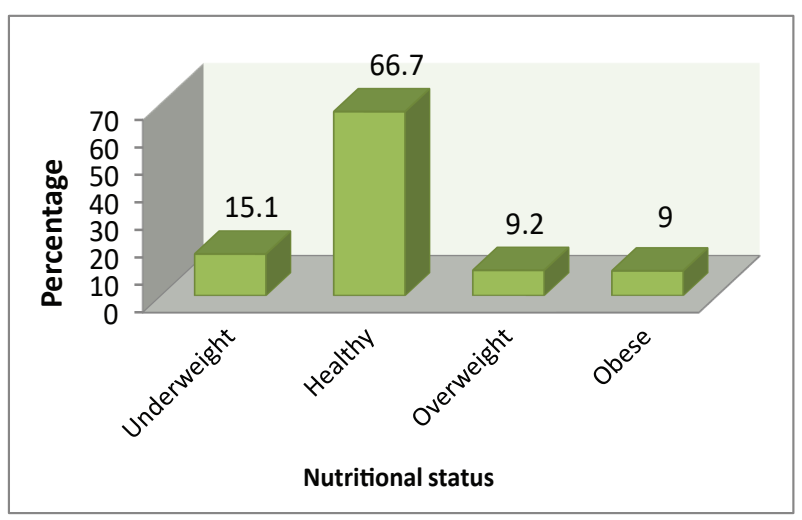

Fig 2: Distribution of students by their nutritional status $(n=535)$

Data pertaining to dietary behavior of the students are shown in Table II. Majority (85\%) of the students informed that they always take breakfast, $7.9 \%$ take it often, $6 \%$ take it sometimes and $1.1 \%$ never takes breakfast. Of the total students, 243(45.4\%) told that they take fruits every day. Sixty percent of the students used to take vegetables every day. Nearly half $(49.2 \%)$ of the students told that their major meal was based on a balanced mixes of carbohydrate, protein and fat, while $27.3 \%$ of the students' major meal was predominantly composed of carbohydrate, $20.2 \%$ predominantly of protein and $3.4 \%$ predominantly of fat. Two-thirds $(66 \%)$ of the students used to take biscuits or breads or crackers as their light meals (snacks), 17\% take fruits or milk or yoghurt, $12.1 \%$ sweet, ice-cream or chocolate and only a few have had their light with Burger/Soft-drink/Pizza/Fried-chicken/Grill. Majority $(82.7 \%)$ of the students who take fruits everyday ( $n$ = 243) takes them 1-2 times a day, $14.8 \% 3-4$ servings a day and only $2.5 \% 5$ or more servings a day (Fig. 3). 
Out of 535 respondents, 360(67.3\%) informed that they took exercise regularly. Types of exercise/sports practiced by the students are illustrated in Fig. 4. The predominant form of exercise practiced by them was running $(65 \%)$ followed by cycling $(64.4 \%)$, cricket $(63.6 \%)$, football $(57.2 \%)$, fast walking $(52.2 \%)$. Other less commonly practiced forms of exercise were outdoor games $(41.9 \%)$, jogging $(30.8 \%)$ and formal exercises (18.9\%) (Fig. 4). Those who took exercise regularly, $247(68.6 \%)$ of them were used having exercise 5-7 days in a week and the rest $113(31.4 \%)<5$ days a week. Nearly $90 \%$ of them used to take exercise 30 minutes or more a day. Watching TV was the main way of pastime $(85.2 \%)$ followed by listening music $(80 \%)$, reading a book $(72 \%)$, playing games or other activities on mobile (58.9\%), shopping (52.5\%), gardening (51.6\%) and using a computer (Fig. 5). Over two-thirds $(67.9 \%)$ of the respondents spent 1 or $<1$ hour on watching TV/computer/mobile etc. Those respondents who did take any kinds of exercise $(n=175)$ were asked to mention the reasons of reluctance to take exercise. The predominant reason reported by the students was going to coaching or private tutor $(79.4 \%)$, parents do not encourage playing $(71.4 \%)$, school/ teachers do not encourage playing (65.5\%), no playing field nearby home $(58.9 \%)$, no leisure time to play $(30.3 \%)$ and no playing field in the school $(7.9 \%)$ (Table III).

Asked about what a healthy diet comprised of, over $60 \%$ respondents told diet rich in different foods, $23.2 \%$ told diet rich in protein, $13.3 \%$ opined diet rich in carbohydrate and only $1.9 \%$ told diet rich in fat. As opinion about a healthy diet was sought, out of a number of choices, approximately $85 \%$ of the respondents told fresh food, $8.4 \%$ told processed food and $7.3 \%$ told foods without preservative and additives. Opinion sought from the respondents about what an energy-rich food is meant for, over them half $(52.5 \%)$ of then opined protein, $31.2 \%$ told carbohydrate and $16.3 \%$ meant fat. Asked about whether the respondents themselves were able to make healthy choices for food, 363 (67.9\%) nodded that they could do so. Opinion sought about what a balanced diet constitutes, more than $80 \%$ of the respondents told that a diet containing all the nutrients in proportionate amount comprised a balanced diet (Table IV). Girls were healthier $(68.9 \%)$ than their boys counterpart (64\%). Both obesity and underweight were more prevalent among boys than those among girls, although the difference did not turn to significant ( $p=0.233$ ) (Table V).

\begin{tabular}{|c|c|c|}
\hline $\begin{array}{l}\text { Dietary behavior of } \\
\text { the respondents }\end{array}$ & Frequency & Percentage \\
\hline \multicolumn{3}{|l|}{ Take Breakfast } \\
\hline Always & 455 & 85.0 \\
\hline Often & 42 & 7.9 \\
\hline Sometimes & 32 & 6.0 \\
\hline Never & 6 & 1.1 \\
\hline Eat fruits everyday & 243 & 45.4 \\
\hline Take plenty of vegetables everyday & 321 & 60.0 \\
\hline \multicolumn{3}{|l|}{ Major meals based on } \\
\hline High protein & 108 & 20.2 \\
\hline High fat & 18 & 3.4 \\
\hline High carbohydrate & 146 & 27.3 \\
\hline Balanced of mixed diet & 263 & 49.2 \\
\hline \multicolumn{3}{|l|}{ Snacks mainly based on } \\
\hline Fruits/Milk/Yogurt & 91 & 17.0 \\
\hline Biscuits/crackers/bread & 353 & 66.0 \\
\hline \multicolumn{3}{|l|}{ Burger/Soft-drink/Pizza/ } \\
\hline Fried-chicken/Grill & 22 & 4.1 \\
\hline Sweet/lce-cream/Chocolate & 68 & 12.7 \\
\hline
\end{tabular}

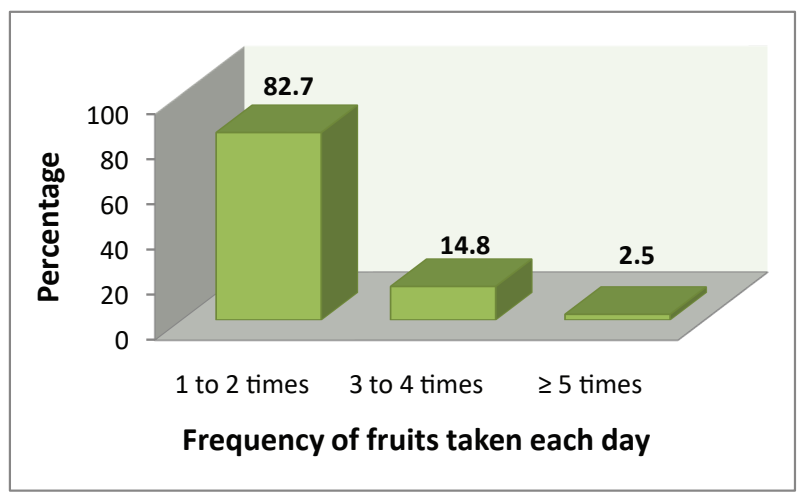

Fig 3: Distribution of students by servings of fruits they take each day $(n=243)$ 


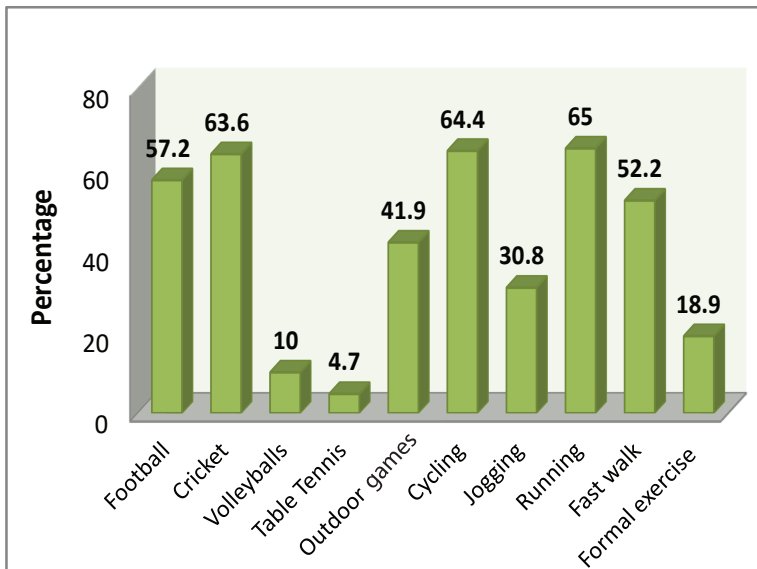

Types of exercise/sports practiced

Fig 4: Students stratified by types of exercise/sports practiced by the them $(n=360)$

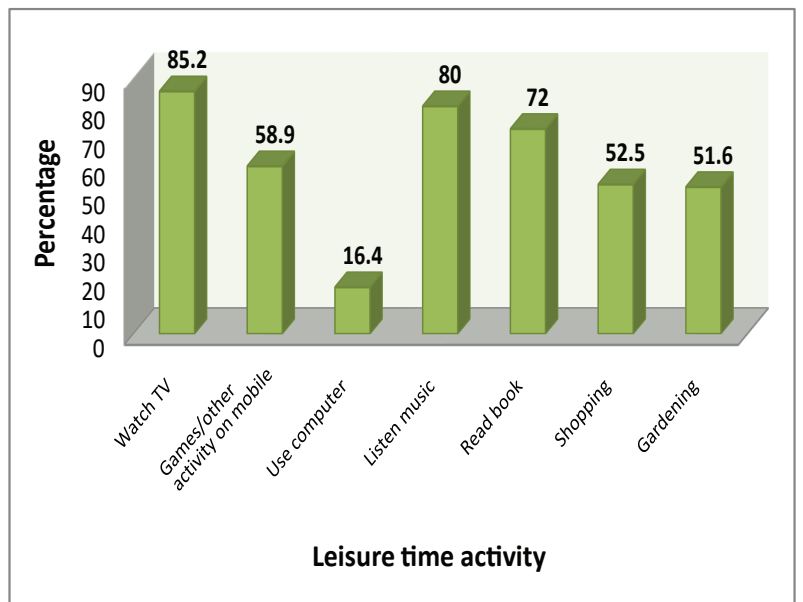

Fig 5: Distribution of students by their leisure time activities $(n=535)$

Table III. Reasons of not taking any kinds of exercise $\left(n=175^{*}\right)$

\section{Reasons} Frequency

Percentage

No leisure time to play

Go coaching or private tutor

No playing field in the school

No playing field nearby home

103

School/teachers do not

encourage to play

Parents do not encourage playing

125

*Total will not correspond to $100 \%$ for multiple response
Tab IV. Students stratified by their opinion about a healthy diet, food, balanced diet $(n=535)$

Opinion

Frequency Percentage

Which of the following

dietshealthy diets

Diet rich in different foods $\quad 330 \quad 61.7$

Diet rich in protein $\quad 124 \quad 23.2$

Diet rich in carbohydrate $\quad 71$

Diet rich in fat

Which of the following foods

are healthy food

Fresh food

84.3

Processed food

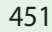

8.4

Foods without preservatives and additives

Which of the following foods are energy-rich food

$\begin{array}{lcc}\text { Protein } & 281 & 52.5 \\ \text { Carbohydrate } & 167 & 31.2 \\ \text { Fat } & 87 & 16.3\end{array}$

Which of the following diets

is a balanced diet

Diet rich in protein $\quad 66 \quad 12.3$

Diet poor in carbohydrate

All the nutrients in

proportionate amounts

437

81.7

Table V. Association between sex and nutritional stats

\begin{tabular}{lccc}
$\begin{array}{l}\text { Nutritional status } \\
\text { (based on BMI) }\end{array}$ & \multicolumn{2}{c}{ Sex } & \\
\cline { 2 - 3 } & $\begin{array}{c}\text { Boys } \\
(n=242)\end{array}$ & $\begin{array}{c}\text { Girls } \\
(n=293)\end{array}$ & -value \\
\hline Healthy (5th $-<85$ th percentile) & $155(64.0)$ & $202(68.9)$ & \\
Overweight (85th -<95th percentile) & $19(7.9)$ & $30(10.2)$ & 0.233 \\
Obese ( $\geq 95$ th percentile) & $26(10.7)$ & $22(7.5)$ & \\
Underweight (<5th percentile) & $42(17.4)$ & $39(13.3)$ &
\end{tabular}

Figures in the parentheses denote corresponding percentage. Data were analyzed using Chi-square $\left(\gamma^{2}\right)$ Test

\section{DISCUSSION:}

In the present study $15 \%$ of the secondary school children were found underweight and $18 \%$ were overweight or obese. Finding underweight adolescents in a rural area is not unusual, but if overweight and obese adolescents exceed the 
underweight ones, it is really a cause of concern. About $65 \%$ of the of the respondents' family were more or less economically solvent (belonging to middle class, upper middle class and rich). Once underweight was a problem among adolescents living in rural areas of Bangladesh and overweight and obesity was rarely reported. With the improvement of economic status, nutritional status has changed a lot. Now underweight is gradually decreasing with consequent increase in the incidence of overweight and obesity and the country is experiencing a double burden of malnutrition. This pattern of change in nutritional status (rising of overweight/obesity epidemics) is the characteristics of all developing countries and is attributed by rapid economic and epidemiologic transition, caused by several socioeconomic and demographic changes that reflects the profound changes in the society. ${ }^{11-14}$ Numerous obesity-related co-morbidities can develop during childhood, which include cardiovascular risk factors such as hypertension, insulin resistance and hyperlipidaemia, even in very young children and conditions such as sleep apnoea, asthma, liver disease, and type 2 diabetes mellitus. Evidence also shows that childhood obesity can track into adulthood, \& is therefore associated with an increased risk of ill-health later in life. ${ }^{15}$ The data of changing nutritional status in the present study, thus is indicative of increased prevalence of non-communicable diseases in the future and leaves scope for health authority and school authority to simultaneously address the issue. Exposing children to balanced nutrition throughout childhood reinforces lifelong eating habits thus contributing to children's overall well-being and helping them enjoy a healthy and fulfilling life in the future.

As dietary behavior of the adolescents was analyzed, $50 \%$ of the adolescents reported that they were accustomed to a healthy balanced diet with $45 \%$ reportedly taking fruits every day and $60 \%$ taking plenty of vegetables every day. But further probing revealed that out of $45 \%$ who reported taking fruits every day, only $17.3 \%$ took 3 or more servings of fruits a day. As "Food-guide Pyramid" recommends 2-4 servings of fruits to maintain a balanced diet, $82.7 \%$ of the adolescents in the present study cannot be considered maintaining a balanced diet in terms fruits intake. In terms of intake of vegetables, $40 \%$ of the adolescents' daily diet does not contain enough vegetables, which might have unfavorably affected their health. Thirty percent of the adolescents were used to having high carbohydrate and fat which might have contributed to the development of overweight and obesity. In terms of exercise practice, two-thirds $(67.3 \%)$ of the students had healthy practice. The predominantly practiced exercise was running (65\%) followed by cycling $(64.4 \%)$, cricket $(63.6 \%)$, football $(57.2 \%)$, fast walking $(52.2 \%)$. However, with respect to number of days of exercise in a week and duration of exercise each day a sizable portion of the students' practice cannot be considered an ideal one.

The respondents who did not practice any exercise or sports activities were asked to mention the reasons behind their unhealthy behavior. The most frequently mentioned reason was 'preoccupation with coaching or private tutors' $(79.4 \%)$, followed by non-encouragement of playing by their parents $(71.4 \%)$ and teachers $(65.5 \%)$. Nearly $60 \%$ of the respondents were interested to play but they did not have any playing field nearby home or inside the school to play. These days as a result of urbanization, priority is shifting to using space for new buildings, condominiums (which represent a dramatic shift in housing), roads, and car parks instead of children's recreational and play areas. ${ }^{16}$ The school environment clearly affects the level of physical activity and overweight/obesity of in-school adolescents, since they spend the majority of their time in schools. ${ }^{17}$ Thus, the nutritional status of the adolescents as depicted in the present study is not only due to negligence of health authority. The education authority is equally liable for their unwanted nutritional status. Finding a sustainable solution to this problem lies in the combined and coordinated action of both Health and Education Ministries.

Once playing was considered as a part of education and almost every student used to play in the school-field. Playing outdoor games not only helps to build health, it immensely contributes to moral and social development as well. As the sole purpose of education was to build character, playing was considered indispensable for attaining the purpose of 
education. When education was begun to be viewed as a lucrative, profit-making business by the teachers or by some vested quarters, the coaching-centers began to flourish with rote-learning and modelquestion solving by the students became the priority activities. The learning became coaching-center dependent \& students were bound to invest their leisure-time in coaching centers instead of playing in the field. The resulting physical inactivity led them to be overweight and obese. So the deep-rooted cause of this problem lies in the reorientation of our education system with playing being considered as part and parcel for attaining the educational goal. There is pressing need for nutrition education to extend down to secondary school children.

Another concern raised from the findings of the study is that one-third of the students pass $>1$ hour of their leisure time by watching TV or sitting at computer or playing games or other activities on mobile. This newer addiction of young generations is harmful in many respects. It not only leads to inactivity with consequent accumulation of risk factors of non-communicable diseases, it also adversely affects the mental and social health of the users.

Finally, opinion-seeking questionnaire revealed the level of knowledge of the respondents about food and diet. There were altogether five questions which helped determine their perception on healthy diet, food, energy-rich food, balanced diet and their ability to make a healthy choice for food. The responses gathered on these variables revealed that $20-50 \%$ of the respondents had misconception in any one of these food and diet-related issues. In this arena, the health authority has wider scope to work and it is their undeniable responsibility to fill in this gap. Had the health authority launched a mass behavior change communication among the school-level children and adolescents, an unprecedented healthy dietary \& exercise behavior could have been resulted.

\section{CONCLUSION:}

From the findings of the study, it can be concluded that every 1 in 6 secondary school children in rural area suffers from underweight, while every 1 in 5 children suffers from overweight or obesity.
Unhealthy dietary behavior, either in terms of balanced diet or in terms of protective food, is rampantly prevailing among secondary school adolescents in rural area. About one-third of the rural secondary school children are physically inactive and reasons of being inactive are predominantly 1) going to coaching center or private tutors, 2) no incentive for playing from the parents or teachers. Even, those who intend to play, they cannot do it, because of absence of a plying field nearer to their home or in the school. Besides, their knowledge level on healthy diet and food is not up to the desired level to make healthy choices for themselves. Both unhealthy dietary behavior and inactivity might have contributed to inappreciably adverse nutritional status of the secondary level school children.

\section{REFERENCES:}

1. World Health Organization Obesity: preventing \& managing the global epidemic. 1998 [cited 2018 Jun 15]. Available from: http://apps.who.int/iris/handle/10665/ 63854.

2. Ng M, Fleming T, Robinson M, Thomson B, Graetz N, Margono C, et al. Global, regional and national prevalence of overweight and obesity in children and adults during 1980-2013: a systematic analysis for the Global Burden of Disease Study 2013. Lancet 2014;384:766-81.

3. de Onis M, Blossner M, Borghi E. Global prevalence and trends of overweight and obesity among preschool children. Am J Clin Nutr 2010;92(5):1257-264. doi:10. 3945/ajcn.2010.29786.

4. Dennison ME, Sisson SB, Lora K, Stephens LD, Copeland KC, Caudillo C. Assessment of body mass index, sugar sweetened beverage intake and time spent in physical activity of American Indian children in Oklahoma. J Community Health 2015;40(4):808-14. doi: 10.1007/ s10900-015-0004-6.

5. Keane E, Kearney PM, Perry IJ, Kelleher CC, Harrington JM. Trends and prevalence of overweight and obesity in primary school aged children in the Republic of Ireland from 2002-2012: a systematic review. BMC Public Health 2014;14(1): 1. doi: 10.1186/1471-2458-14-974.

6. dos Passos DR, Gigante DP, Maciel FV. Matijasevich a: Children's eating behavior: comparison between normal and overweight children from a school in Pelotas, Rio Grande do Sul, Brazil. Revista Paulista de Pediatria 2015; 33(1):42-49.

7. World Health Organisation, (WHO) (2004). Global Strategy on Diet, Physical Activity \& Health.Geneva. Retrieved from 
www.who.int/dietphysicalactivity/strategy.../strategy_eng lish_web.pdf

8. WHO 2006. A tool for the development of school nutrition programmes in the European Region Programme for Nutrition \& Food Security WHO Regional Office for Europe. Retrieved from www. euro.who.int/_data/assets/pdf_file/ 0019/152218/E89501.pdf

9. Gordon-Larsen P, Adair LS, Nelson MC, Popkin BM. Five-year obesity incidence in the transition period between adolescence and adulthood: The National Longitudinal Study of Adolescent Health. American Journal of Clinical Nutrition 2004;80:569 -75.

10. CDC. Principles of Community Engagement. NIH Publication, 2011;11:7782.

11. Gebremedhin S. Prevalence and differentials of overweight and obesity in preschool children in sub-Saharan Africa. BMJ Open 2015;5(12):e009005. doi: 10.1136/bmjopen2015-009005.,

12. Kyallo F, Makokha A, Mwangi AM. Overweight and obesity among public and private primary school children in Nairobi, Kenya. Health 2013;5(08):85. doi: 10.4236/ health.2013.58A3012.,
13. Nishida C, Uauy R, Kumanyika S, Shetty P. The joint WHO/FAO expert consultation on diet, nutrition and the prevention of chronic diseases: process, product \& policy implications. Public Health Nutr 2004;7(1A):245-50.

14. Elías-Boneta AR, Toro MJ, Garcia O, Torres R, Palacios C. High prevalence of overweight and obesity among a representative sample of Puerto Rican children. BMC Public Health 2015;15(1):1. doi: 10.1186/s12889-0151549-0.

15. Al-Khudairy L, Loveman E, Colquitt JL, Mead E, Johnson $\mathrm{RE}$, Fraser $\mathrm{H}$ et al. Diet, physical activity and behavioural interventions for the treatment of overweight or obese adolescents aged 12 to 17 years. Cochrane Database Syst Rev 2017;2017(6):CD012691. Published online 2017 Jun 22. doi: $10.1002 / 14651858 . C D 012691$

16. Gebregergs GB, Yesuf ME, Beyen TK. Overweight and obesity, and associated factors among high school students in Gondar town, north west Ethiopia. J Obes Wt Loss Ther 2013;3:1000165.

17. Trang NH, Hong TK, Dibley MJ. Cohort profile: Ho Chi Minh City Youth Cohort- changes in diet, physical activity, sedentary behavior and relationship with overweight/ obesity in adolescents. BMJ Open 2012;2:e000362 